\title{
Ixekizumab and Ustekinumab Efficacy in Nail Psoriasis in Patients with Moderate-to-Severe Psoriasis: 52-Week Results from a Phase 3, Head-to-Head Study (IXORA-S)
}

\author{
Norman Wasel · Diamant Thaçi · Lars E. French • Curdin Conrad • \\ Yves Dutronc · Gaia Gallo · Lovisa Berggren · Jean-Philippe Lacour
}

Received: March 5, 2020 / Published online: May 15, 2020

(C) The Author(s) 2020

\section{ABSTRACT}

Introduction: Patients with plaque psoriasis often have nail psoriasis, which is difficult to treat. Ixekizumab (IXE) and ustekinumab (UST) are biologics with established efficacy in nail psoriasis. We present post hoc data from a head-

Digital Features To view digital features for this article go to https://doi.org/10.6084/m9.figshare.12179274.

N. Wasel $(\bowtie)$

Stratica Medical and Probity Medical Research, Edmonton, AB, Canada

e-mail: nwasel@straticamedical.com

D. Thaçi

Research Institute and Comprehensive Center for Inflammation Medicine, University of Lübeck,

Lübeck, Germany

L. E. French

Department of Dermatology and Allergy, University Hospital, Ludwig Maximilian University of Munich (LMU Munich), Munich, Germany

C. Conrad

Department of Dermatology, Lausanne University

Hospital (CHUV), Lausanne, Switzerland

Y. Dutronc · G. Gallo

Eli Lilly and Company, Indianapolis, IN, USA

L. Berggren

HaaPACS GmbH, Schriesheim, Germany

J.-P. Lacour

Department of Dermatology, University Hospital of

Nice-Côte d'Azur, Nice, France to-head trial of IXE and UST (IXORA-S) to examine the efficacy in nail psoriasis in patients with moderate-to-severe plaque psoriasis over 52 weeks.

Methods: In IXORA-S, randomised patients received IXE $(N=136)$ or UST $(N=166)$ per label for 52 weeks. Eighty-four (61.8\%) and 105 $(63.3 \%)$ of the patients treated with IXE or UST, respectively, had baseline fingernail psoriasis (Nail Psoriasis Severity Index [NAPSI] $>0$ ); of these, $54(64.3 \%)$ and $63(60.0 \%)$ patients, respectively, had significant baseline fingernail psoriasis (defined as NAPSI $\geq 16$ with $\geq 4$ fingernails involved). The proportion of patients achieving NAPSI $=0$, a NAPSI score change from baseline and correlations in Psoriasis Area of Severity Index (PASI) and NAPSI improvement over 52 weeks were examined.

Results: Progressive improvement occurred in both treatment groups over 52 weeks. Statistically significantly more patients achieved NAPSI $=0$ with IXE versus UST by week 16-20, and the proportions continued to increase through week 52 among patients with baseline nail psoriasis (61.9 vs. $28.6 \%$, respectively; $P<0.001)$, including those with significant nail psoriasis (57.4 vs. $17.5 \%$, respectively; $P<0.001)$. Similar results were observed for NAPSI score improvement from baseline to week 52. Interestingly, the presence of nail psoriasis was associated with lower skin response with UST but not with IXE. 
Conclusions: Ixekizumab was superior to UST in the clearance of nail psoriasis, with earlier improvement continued through 52 weeks regardless of baseline nail severity.

Trial Registration: ClinicalTrials.gov identifier; NCT02561806.

Keywords: Ixekizumab; Nail psoriasis; Psoriasis; Ustekinumab

\section{Key Summary Points}

Why carry out this study?

Nail psoriasis is common in patients with psoriasis but is particularly difficult to treat.

IXORA-S was a randomised, double-blind, head-to-head comparison of the efficacy and safety of ixekizumab (IXE) and ustekinumab (UST) in patients with moderate-to-severe psoriasis.

This post hoc analysis was performed to directly compare IXE and UST efficacy in the clearance of nail psoriasis or significant nail psoriasis up to 52 weeks.

\section{What was learned from the study?}

Ixekizumab was shown to be superior to UST in providing earlier complete clearance of nail psoriasis with continued improvement through 52 weeks, regardless of baseline nail severity.

The presence of nail psoriasis was associated with a lower rate of skin clearance among UST-treated patients, but this was not the case for IXE-treated patients, who had similar skin response whether nail psoriasis was present or not.

\section{INTRODUCTION}

Psoriasis is a chronic, inflammatory skin condition that frequently affects the nails. The prevalence of nail psoriasis varies from 10 to $82 \%$, and the majority $(80-90 \%)$ of patients with psoriasis will experience nail psoriasis during their lifetime $[1,2]$. Nail psoriasis is also prevalent in patients with psoriatic arthritis (PsA), and it has been considered a predictor for the development of PsA [2-5]. Nail psoriasis can cause pain and can impair hand mobility [6].

Nail psoriasis is difficult to treat. The anatomy of the nail presents therapeutic challenges, as topical agents may not penetrate the nail plate to reach sites of inflammation in the nail bed or matrix [4]. Local injections of therapeutic agents to the nail matrix can be used but these are painful, and the efficacy of systemic therapies is mixed or data are limited [4]. In addition, as nails grow slowly, the resolution of psoriasis lesions with local or systemic treatments may take up to 1 year [4]. Several biologic therapies are approved for the treatment of moderate-tosevere plaque psoriasis [7], including ixekizumab (IXE), a high affinity immunoglobulin (Ig) G4 monoclonal antibody that selectively acts as an interleukin-(IL)-17A antagonist $[8,9]$,

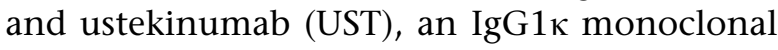
antibody that binds with specificity to inhibit the p40 subunit of IL-12/23 [10, 11]. Pivotal phase 3 trials for both IXE [12, 13] and UST $[14,15]$ have shown a significant efficacy of at least $75 \%$ in the Psoriasis Area and Severity Index (PASI 75) for moderate-to-severe psoriasis, ranging from $87 \%$ to $90 \%$ for IXE and from $65 \%$ to $78 \%$ for UST [7]. Both drugs also have been shown to statistically significantly improve nail psoriasis within 1 year $[16,17]$, but they have not been compared directly in a head-to-head trial. Such comparative studies are important for helping make suitable decisions based on specific therapeutic goals $[16,18,19]$.

The aim of the analysis presented here was to examine the efficacy of IXE and UST in the treatment of nail psoriasis in patients with moderate-to-severe psoriasis over 52 weeks of treatment.

\section{METHODS}

\section{Study Design}

IXORA-S was a 52-week, phase $3 \mathrm{~b}$, multicentre, randomised, double-blind, head-to-head trial in 
which eligible patients with moderate-to-severe plaque psoriasis were randomised $(1: 1)$ to receive either IXE (160-mg starting dose administered as two $80-\mathrm{mg}$ injections, then $80 \mathrm{mg}$ every 2 weeks for 12 weeks followed by $80 \mathrm{mg}$ every 4 weeks; $N=136)$ or UST (45-mg/90-mg weight-based dosing at weeks 0,4 and every 12 weeks thereafter per label; $N=166$ ) [20,21]. No concomitant psoriasis treatments were allowed during the trial. This trial was registered with clinicaltrials.gov (NCT02561806) and EudraCT (2015-00089228).

The study was approved by the applicable ethical review boards at each participating study site, and was conducted in accordance with the principles expressed in the Declaration of Helsinki of 1964 and its subsequent amendments. Written, informed consent was obtained from each patient at study entry before any study procedures took place.

\section{Nail Evaluations}

The Nail Psoriasis Severity Index (NAPSI) was used to assess fingernail psoriasis for all patients who presented with fingernail psoriasis at baseline. Each fingernail was scored for bed and matrix psoriasis. Scores were summed to obtain total NAPSI fingernail scores ranging from 0 (no nail psoriasis) to 80 (severe nail psoriasis). As some patients may have had limited nail psoriasis, we also looked at patients with moderateto-severe nail psoriasis (later referred to as "significant nail psoriasis"), defined as fingernail NAPSI $\geq 16$ and $\geq 4$ fingernails involved [16]. NAPSI scores were not collected for patients who did not have nail psoriasis.

\section{Statistical Analyses}

Categorical data for treatment groups were assessed via logistic regression, with treatment, weight $(\leq 100 \mathrm{~kg},>100 \mathrm{~kg})$, and geographic region (Western European Union [EU], Eastern EU, North America) as factors. Fisher's exact test was used for comparison. Missing data were imputed using non-responder imputation.

For continuous variables, least squares means [95\% confidence interval (CI)] were calculated for NAPSI, and treatment groups were compared using analysis of covariance, with treatment, weight ( $\leq 100 \mathrm{~kg},>100 \mathrm{~kg}$ ), geographic region (Western EU, Eastern EU, North America) and baseline NAPSI score as factors. Missing data were imputed using modified baseline observation carried forward.

Statistical significance was set at $P$ value $<0.05$. No multiplicity correction was done for the nail endpoints as per study protocol.

\section{RESULTS}

Patients in the IXORA-S intent-to-treat population were treated with IXE $(N=136)$ or UST $(N=166)$ for 52 weeks. Eighty-four $(61.8 \%)$ patients randomised to IXE and 105 (63.3\%) patients randomised to UST had nail psoriasis at baseline; of these, 54 (64.3\%) and 63 (60.0\%) patients treated with IXE and UST, respectively, had significant nail psoriasis at baseline. Overall, patients with nail psoriasis had higher baseline PASI scores, longer duration of plaque psoriasis and a greater proportion of PsA than patients without nail psoriasis. Mean baseline NAPSI ( \pm standard deviation [SD]) scores were $28.3( \pm 19.9)$ and $24.8( \pm 20.0)$ in the IXE and UST treatment groups, respectively (Table 1 ).

Progressive improvement was observed in both treatment groups (Figs. 1, 2). Statistically significantly more patients with baseline nail psoriasis achieved complete resolution $($ NAPSI $=0)$ with IXE than with UST by week 16 (31.0 vs. $16.2 \% ; P=0.02)$ through week 52 (61.9 vs. $28.6 \% ; P<0.001)$ (Fig. 1 , solid lines). Similarly, statistically significantly more patients with significant baseline nail psoriasis achieved complete resolution with IXE than with UST by week 20 (25.9 vs. 9.5\%; $P=0.03)$ through week 52 (57.4 vs. $17.5 \% ; P<0.001)$ (Fig. 1, dashed lines).

Average improvement in NAPSI score was statistically significantly greater for IXE-treated patients by week $8(-6.6$; $95 \% \mathrm{CI}-8.9,-4.3)$ than for UST $(-2.1 ; 95 \%$ CI $-4.1,-0.1)$ $(P=0.002) \quad$ (Fig. 2). Improvement remained statistically significantly greater with IXE through week $52(-22.4 ; 95 \%$ CI -24.8 , 
Table 1 Baseline characteristics of patients with and without nail involvement at baseline in the IXORA-S intent-to-treat population

\begin{tabular}{lll}
\hline Baseline characteristics of patients $^{\mathbf{a}}$ & Ustekinumab $(\boldsymbol{N = \mathbf { 1 6 6 } )}$ & Ixekizumab $(\boldsymbol{N}=\mathbf{1 3 6})$ \\
\hline Patients with baseline nail psoriasis & $105(63.3 \%)$ & $84(61.8 \%)$ \\
Age (years) & $45.4 \pm 12.7$ & $43.0 \pm 12.0$ \\
Sex (male) & $80(76.2 \%)$ & $60(71.4 \%)$ \\
Weight (kg) & $91.3 \pm 24.4$ & $87.5 \pm 21.7$ \\
Weight $>100.0 \mathrm{~kg}$, & $34(32.4 \%)$ & $22(26.2 \%)$ \\
PASI score & $21.1 \pm 9.2$ & $20.2 \pm 9.0$ \\
sPGA score & $3.7 \pm 0.6$ & $3.7 \pm 0.7$ \\
Duration of plaque psoriasis (years) & $20.2 \pm 11.8$ & $19.4 \pm 12.0$ \\
NAPSI score & $24.8 \pm 20.0$ & $28.3 \pm 19.9$ \\
Significant baseline nail psoriasis ${ }^{\mathrm{b}}$ & $63(60.0 \%)$ & $54(64.3 \%)$ \\
Presence of psoriatic arthritis & $18(17.1 \%)$ & $17(20.2 \%)$ \\
Patients without baseline nail psoriasis & $61(36.7 \%)$ & $52(38.2 \%)$ \\
Age (years) & $41.6 \pm 14.0$ & $42.3 \pm 13.8$ \\
Sex (male) & $32(52.5 \%)$ & $30(57.7 \%)$ \\
Weight (kg) & $86.1 \pm 25.3$ & $83.0 \pm 17.7$ \\
Weight $>100.0$ kg & $11(18.0 \%)$ & $9(17.6 \%)$ \\
PASI score & $17.7 \pm 8.3$ & $19.5 \pm 6.6$ \\
sPGA score & $3.6 \pm 0.6$ & $3.5 \pm 0.5$ \\
Duration of plaque psoriasis (years) & $14.9 \pm 11.6$ & $15.8 \pm 9.2$ \\
Presence of psoriatic arthritis & $6(9.8 \%)$ & $7(13.5 \%)$ \\
\hline
\end{tabular}

$N$ number of patients, NAPSI Nail Psoriasis Severity Index, PASI Psoriasis Area of Severity Index, sPGA static Physicians Global Assessment

${ }^{a}$ Values for baseline characteristics are presented as the mean \pm standard deviation (SD) or as the number of patients with the percentage in parenthesis, as appropriate

b Defined as fingernail NAPSI $\geq 16$ and $\geq 4$ fingernails involved

- 20.0) compared with UST (- 15.6; $95 \%$ CI $17.8,-13.4)(P<0.001)$ (Fig. 2).

Patients treated with UST had lower clearance of plaque psoriasis when nail psoriasis was present compared to when nail psoriasis was absent. At week 52, PASI 100 response rates, denoting the percentage of patients achieving $100 \%$ clearance of skin plaques, were $27.6 \%$ when nail psoriasis was present versus $49.2 \%$ when nail psoriasis was absent (Fig. 3). In contrast, patients treated with IXE had similar skin responses throughout the treatment period whether nail psoriasis was present or absent. At week 52, the PASI 100 response rates were $53.6 \%$ when nail psoriasis was present and $50.0 \%$ when nail psoriasis was absent (Fig. 3). Similar observations were made for PASI 100 response rates at week 24 and for PASI 75/90 response rates at weeks 24 and 52 . 


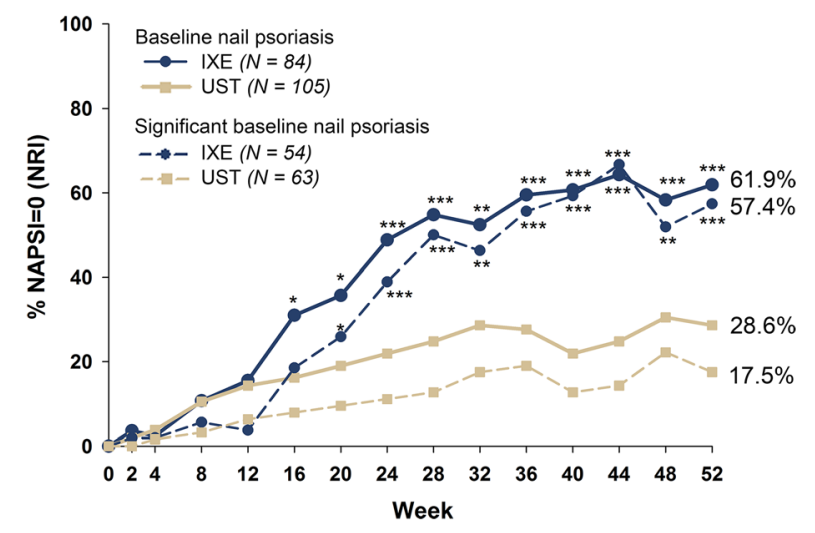

Fig. 1 Complete resolution (Nail Psoriasis Severity Index $[N A P S I]=0)$ response rates for patients treated with ixekizumab (IXE) or ustekinumab (UST) from week 0 to week 52 . Solid lines are patients with baseline nail psoriasis (NAPSI $>0)$; asterisks are $P$ values for solid line. Dashed lines are patients with significant baseline nail psoriasis (NAPSI $\geq 16$ and $\geq 4$ fingernails involved); asterisks are $P$ values for dashed line. NAPSI $=0$ response rates were calculated via nonresponder imputation (NRI). ${ }^{* * *} P<0.001,{ }^{* *} P<0.01,{ }^{*} P<0.05$ via Fisher's exact test. $N$ Number of patients

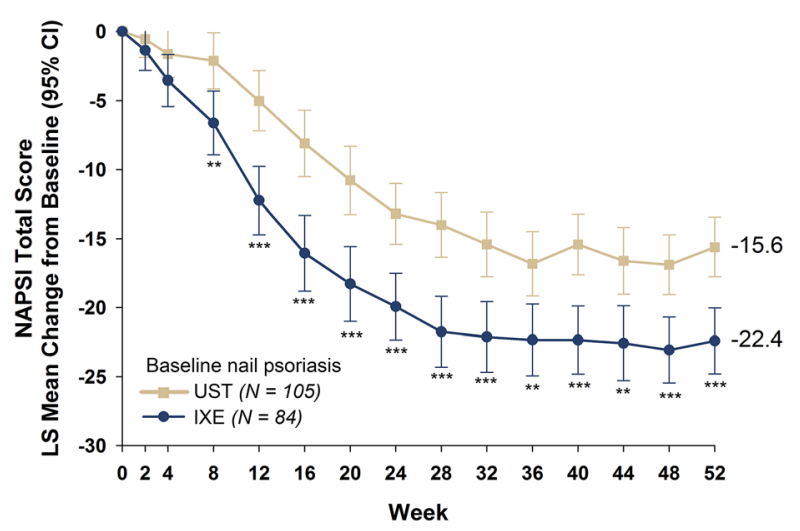

Fig. 2 Change from baseline in NAPSI total score for patients with baseline nail psoriasis treated with IXE or UST from week 0 to week 52. Response rates were calculated via analysis of covariance, with missing data imputed using modified baseline observation carried forward. ${ }^{* *} P<0.001,{ }^{* *} P<0.01,{ }^{*} P<0.05$, least square $(L S)$ mean difference between treatment groups. CI confidence interval, $N$ number of patients

For most patients with nail psoriasis, total NAPSI and PASI scores improved together by week 24, with concurrent improvement continued through week 52 in both treatment groups. In general, PASI total scores improved more rapidly than NAPSI total scores, and for some patients, NAPSI scores remained higher at week 52 despite reduction in plaque psoriasis burden in both treatment groups. At week 52, the percentages of patients who still presented with significant nail psoriasis were $7.8 \%$ and 21.5\% $(P=0.02)$ for patients treated with IXE and UST, respectively.

\section{DISCUSSION}

While improvement in nail psoriasis was observed in IXE and UST treatment groups, complete resolution of nail psoriasis was seen in statistically significantly greater percentages of patients treated with IXE compared to UST through 1 year of treatment. Complete clearance was more rapid in patients treated with IXE than UST, as early as week 16 for patients with nail psoriasis or week 20 for patients with significant nail psoriasis. Similarly, there was a statistically significant improvement in the NAPSI total score in the IXE treatment group by week 8 compared with the UST treatment group, and the superior response with IXE continued through week 52 . These results suggest that IXE may provide significantly greater clearance of nail psoriasis than UST.

Interestingly, among UST-treated patients, the presence of baseline nail psoriasis was associated with a lower rate of skin clearance. This was not the case for IXE-treated patients. Further studies are required to determine if the presence of nail psoriasis is a predictor of the skin response to UST treatment or if this observation is simply due to the fact that, in this trial, patients with nail psoriasis had overall more severe skin involvement and were heavier than those without nail psoriasis. Of note, nail involvement is more frequent in HLA-Cw6 negative patients [22], while HLA-Cw6 presence is a predictor of better clinical response of plaque psoriasis with UST treatment. No difference was observed in anti-IL-17A (secukinumab)treated patients with regards to HLA-Cw6 status $[23,24]$. These data suggest that patients with nail involvement might have a better predicted outcome in skin plaque psoriasis with IXE 


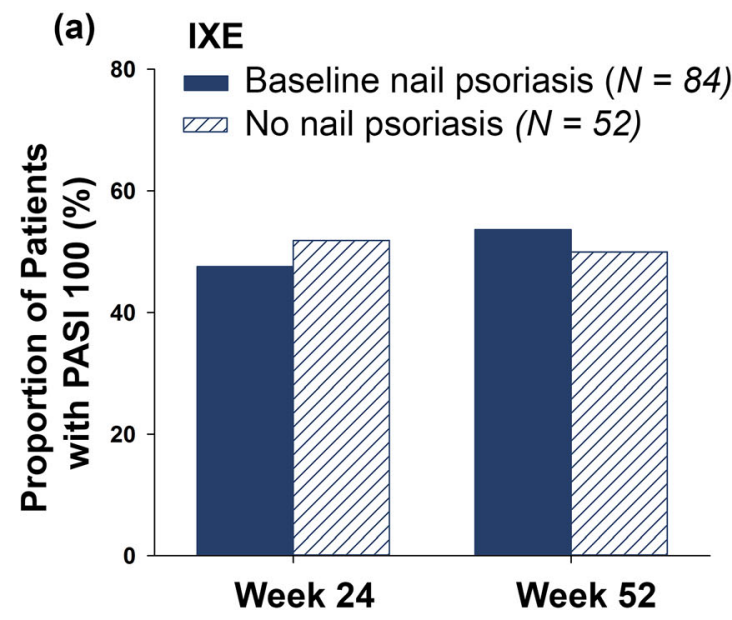

Fig. 3 Proportion of patients with and without baseline nail psoriasis (solid and pattern bars, respectively) who achieved $100 \%$ clearance of skin plaques based on Psoriasis

treatment than with UST treatment. Determining HLA-Cw6 status may be of interest in further studies evaluating the efficacy of new biologics in nail psoriasis.

NAPSI and PASI total scores generally improved simultaneously for many patients over 52 weeks. Nevertheless, a dissociation between skin and nail improvement was seen for some patients who had very good skin response but retained significant nail lesions (low PASI total score with high NAPSI total score). This observation highlights the importance of studying nail psoriasis response with approved or emerging therapies, as it cannot be assumed that efficacy in skin lesions will translate to nail psoriasis resolution as well.

IXORA-S was a randomised, controlled, head-to-head trial comparing IXE and UST, but a limitation was that nail psoriasis was not a stratification factor in the trial. Nevertheless, patients with and without baseline nail psoriasis, including those with significant involvement, had comparable representation in each treatment group in the post hoc analyses. IXE and UST were administered in this study per label at the approved dosage regimen for the treatment of adult patients with moderate-tosevere psoriasis $[9,11]$, but real-world dosing may differ. A longer period of observation is required to determine if nail lesions will

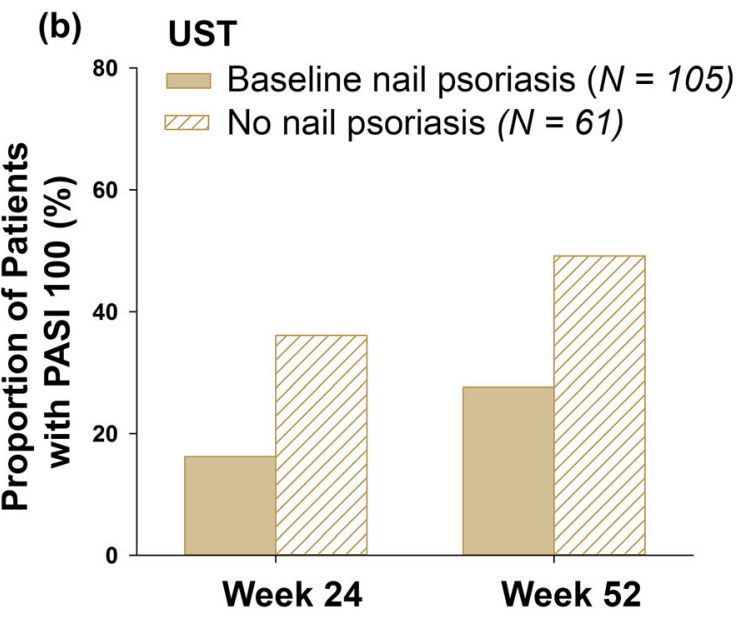

Area and Severity Index score (PASI 100) at weeks 24 and 52 with IXE (a) or UST (b) treatment. PASI response rates were calculated via NRI. $N$ number of patients

continue to improve beyond 1 year of treatment, as the duration of this observation in the current study may still be too short to assess complete benefit.

\section{CONCLUSIONS}

Ixekizumab showed greater ability to clear both skin and nail psoriasis than UST at 1 year of treatment.

\section{ACKNOWLEDGEMENTS}

The authors would like to thank the patients for their involvement in the study.

Funding. This study was sponsored by Eli Lilly and Company (Indianapolis, IN, USA). Eli Lilly and Company is also funding the journal's Rapid Service Fees.

Authorship. All named authors meet the International Committee of Medical Journal Editors (ICMJE) criteria for authorship for this article, take responsibility for the integrity of the work as a whole, and have given their approval for this version to be published. 
Medical Writing Assistance. Medical writing services were provided by Melody Pupols, PhD, of Syneos Health, and support for this assistance was funded by Eli Lilly and Company.

Prior Presentation. Portions of this work were presented at the 27th European Academy of Dermatology and Venereology Congress in Paris, France; September 12-16, 2018.

Disclosures. Norman Wasel has served as an advisor, investigator and speaker, and has received grants and honoraria from Abbott, AbbVie, Amgen, Boehringer Ingelheim, BristolMyers Squibb, Dermira, Eli Lilly and Company, Janssen, Merck, Merck-Serono, Novartis, Pfizer and UCB. Diamant Thaçi has been a consultant and advisor and/or received speaking fees and/ or grants and/or served as an investigator in clinical trials for the following companies: AbbVie, Almirall, Amgen, Asana, Bioskin, Biogen, Biocad, Boehringer Ingelheim, Bristol-Myers-Squib, Celgene, Dermira, DS-Biopharma, Eli Lilly and Company, Galapagos, Galderma, LEO Pharma, Janssen-Cilag, Kymab, Merck Sharp Dohme, Morphosis, Novartis, Pfizer, Regeneron, Roche, Sandoz, Sanofi, Samsung and UCB. Lars E. French has served as an advisor and investigator, and has received honoraria from Amgen, Novartis, Galderma, Janssen-Cilag, Celgene, Eli Lilly and Company and AbbVie. Curdin Conrad has served as a scientific adviser and/or clinical study investigator and/or paid speaker for AbbVie, Actelion, Allmiral, Amgen, Boehringer Ingelheim, Celgene, Eli Lilly and Company, Janssen, LEO Pharma, MSD, Novartis and Pfizer. Yves Dutronc and Gaia Gallo are employees of Eli Lilly and Company, and receive salary and own stock from the company. Lovisa Berggren was an employee of HaaPACS GmbH on behalf of Eli Lilly and Company. Jean-Philippe Lacour is an investigator for, and has received grants from, Amgen, Boehringer Ingelheim, Dermira, Janssen, Pfizer and Regeneron; is an investigator and speaker and has received grants and honoraria from Celgene and AbbVie; is an investigator, speaker and advisory board member and has received grants and honoraria from Eli Lilly and Company, Leo Pharma and Sanofi; and is an investigator, speaker and consultant, and has received grants and honoraria from Novartis.

Compliance with Ethics Guidelines. The study was approved by the applicable ethical review boards at each participating study site, and was conducted in accordance with the principles expressed in the Declaration of Helsinki of 1964 and its subsequent amendments. Written, informed consent was obtained from each patient at study entry before any study procedures took place.

Data Availability. The datasets generated during and/or analysed during the current study are available from the corresponding author on reasonable request.

Open Access. This article is licensed under a Creative Commons Attribution-NonCommercial 4.0 International License, which permits any non-commercial use, sharing, adaptation, distribution and reproduction in any medium or format, as long as you give appropriate credit to the original author(s) and the source, provide a link to the Creative Commons licence, and indicate if changes were made. The images or other third party material in this article are included in the article's Creative Commons licence, unless indicated otherwise in a credit line to the material. If material is not included in the article's Creative Commons licence and your intended use is not permitted by statutory regulation or exceeds the permitted use, you will need to obtain permission directly from the copyright holder. To view a copy of this licence, visit http://creativecommons.org/licenses/by$\mathrm{nc} / 4.0 /$.

\section{REFERENCES}

1. Jiaravuthisan MM, Sasseville D, Vender RB, Murphy F, Muhn CY. Psoriasis of the nail: anatomy, pathology, clinical presentation, and a review of the literature on therapy. J Am Acad Dermatol. 2007;57:1-27.

2. Rigopoulos D, Baran R, Chiheb S, et al. Recommendations for the definition, evaluation, and treatment of nail psoriasis in adult patients with no 
or mild skin psoriasis: a dermatologist and nail expert group consensus. J Am Acad Dermatol. 2019;81:228-40.

3. Wilson FC, Icen M, Crowson CS, McEvoy MT, Gabriel SE, Kremers HM. Incidence and clinical predictors of psoriatic arthritis in patients with psoriasis: a population-based study. Arthritis Rheum. 2009;61:233-9.

4. Pasch MC. Nail psoriasis: a review of treatment options. Drugs. 2016;76:675-705.

5. Klaassen KM, van de Kerkhof PC, Pasch MC. Nail psoriasis: a questionnaire-based survey. Br J Dermatol. 2013;169:314-9.

6. Krajewska-Wlodarczyk M, Owczarczyk-Saczonek A, Placek W, Wojtkiewicz M, Wiktorowicz A, Wojtkiewicz J. Ultrasound assessment of changes in nails in psoriasis and psoriatic arthritis. Biomed Res Int. 2018. https://doi.org/10.1155/2018/8251097.

7. Kaushik SB, Lebwohl MG. Review of safety and efficacy of approved systemic psoriasis therapies. Int J Dermatol. 2019;58:649-58.

8. Liu L, Lu J, Allan BW, et al. Generation and characterization of ixekizumab, a humanized monoclonal antibody that neutralizes interleukin-17A. J Inflamm Res. 2016;9:39-50.

9. Eli Lilly and Company. TALTZ (ixekizumab) [package insert on the Internet]. Indianapolis: Eli Lilly and Company; 2019. https://pi.lilly.com/us/taltzuspi.pdf. Accessed 9 July 2019.

10. Benson JM, Peritt D, Scallon BJ, et al. Discovery and mechanism of ustekinumab: a human monoclonal antibody targeting interleukin-12 and interleukin23 for treatment of immune-mediated disorders. MAbs. 2011;3:535-45.

11. Jannsen Pharmaceutical Companies. STELARA ${ }^{\circledR}$ (ustekinumab) [package insert on the Internet]. Horsham: Jannsen Pharmaceutical Companies. 2019. https://www.janssenlabels.com/packageinsert/product-monograph/prescribing-information/ STELARA-pi.pdf. Accessed 9 July 2019.

12. Griffiths CE, Reich K, Lebwohl M, et al. Comparison of ixekizumab with etanercept or placebo in moderate-to-severe psoriasis (UNCOVER-2 and UNCOVER-3): results from two phase 3 randomised trials. Lancet. 2015;386:541-51.

13. Gordon KB, Blauvelt A, Papp KA, et al. Phase 3 trials of ixekizumab in moderate-to-severe plaque psoriasis. N Engl J Med. 2016;375:345-56.

14. Leonardi CL, Kimball AB, Papp KA, et al. Efficacy and safety of ustekinumab, a human interleukin-
$12 / 23$ monoclonal antibody, in patients with psoriasis: 76-week results from a randomised, doubleblind, placebo-controlled trial (PHOENIX 1). Lancet. 2008;371:1665-744.

15. Papp KA, Langley RG, Lebwohl M, et al. Efficacy and safety of ustekinumab, a human interleukin$12 / 23$ monoclonal antibody, in patients with psoriasis: 52-week results from a randomised, doubleblind, placebo-controlled trial (PHOENIX 2). Lancet. 2008;371:1675-84.

16. Dennehy EB, Zhang L, Amato D, Goldblum O, Rich $P$. Ixekizumab is effective in subjects with moderate to severe plaque psoriasis with significant nail involvement: results from UNCOVER 3. J Drugs Dermatol. 2016;15:958-61.

17. Rich $\mathrm{P}$, Bourcier $\mathrm{M}$, Sofen $\mathrm{H}$, et al. Ustekinumab improves nail disease in patients with moderate-tosevere psoriasis: results from PHOENIX 1. Br J Dermatol. 2014;170:398-407.

18. Papp KA, Leonardi CL, Blauvelt A, et al. Ixekizumab treatment for psoriasis: integrated efficacy analysis of three double-blinded, controlled studies (UNCOVER-1, UNCOVER-2, UNCOVER-3). Br J Dermatol. 2018;178:674-81.

19. Lebwohl M, Strober B, Menter A, et al. Phase 3 studies comparing brodalumab with ustekinumab in psoriasis. N Engl J Med. 2015;373:1318-28.

20. Reich K, Pinter A, Lacour JP, et al. Comparison of ixekizumab with ustekinumab in moderate-to-severe psoriasis: 24-week results from IXORA-S, a phase III study. Br J Dermatol. 2017;177:1014-23.

21. Paul C, Griffiths CEM, van de Kerkhof PCM, et al. Ixekizumab provides superior efficacy compared with ustekinumab over 52 weeks of treatment: results from IXORA-S, a phase 3 study. J Am Acad Dermatol. 2019;80(70-9):e3.

22. Gudjonsson JE, Karason A, Antonsdóttir AA, et al. HLA-Cw6-positive and HLA-Cw6-negative patients with psoriasis vulgaris have distinct clinical features. J Invest Dermatol. 2002;118:362-5.

23. Talamonti M, Botti E, Galluzzo M, et al. Pharmacogenetics of psoriasis: HLA-Cw6 but not LCE3B/3C deletion nor TNFAIP3 polymorphism predisposes to clinical response to interleukin $12 / 23$ blocker ustekinumab. Br J Dermatol. 2013;169:458-63.

24. Costanzo A, Bianchi L, Flori ML, et al. Secukinumab shows high efficacy irrespective of HLA-Cw6 status in patients with moderate-to-severe plaque-type psoriasis: SUPREME study. Br J Dermatol. 2018;179: 1072-80. 